2004

\title{
Analytical Intercomparison Between Flow Injection-Chemiluminescence and Flow Injection- Spectrophotometry for the Determination of Picomolar Concentrations of Iron in Seawater
}

\author{
Andrew R. Bowie \\ Peter N. Sedwick \\ Old Dominion University, Psedwick@odu.edu
}

Paul J. Worsfold

Follow this and additional works at: https://digitalcommons.odu.edu/oeas_fac_pubs

Part of the Biogeochemistry Commons, Marine Biology Commons, and the Oceanography Commons

\section{Repository Citation}

Bowie, Andrew R.; Sedwick, Peter N.; and Worsfold, Paul J., "Analytical Intercomparison Between Flow Injection-Chemiluminescence and Flow Injection-Spectrophotometry for the Determination of Picomolar Concentrations of Iron in Seawater" (2004). OEAS

Faculty Publications. 86.

https://digitalcommons.odu.edu/oeas_fac_pubs/86

\section{Original Publication Citation}

Bowie, A.R., Sedwick, P.N., \& Worsfold, P.J. (2004). Analytical intercomparison between flow injection-chemiluminescence and flow injection-spectrophotometry for the determination of picomolar concentrations of iron in seawater. Limnology and OceanographyMethods, 2, 42-54. doi: 10.4319/lom.2004.2.42 


\title{
Analytical intercomparison between flow injection- chemiluminescence and flow injection-spectrophotometry for the determination of picomolar concentrations of iron in seawater
}

\author{
Andrew R. Bowie ${ }^{1,2^{*}}$, Peter N. Sedwick ${ }^{3,4}$, and Paul J. Worsfold ${ }^{5}$ \\ ${ }^{1}$ Australian Centre for Research on Separation Science, School of Chemistry, University of Tasmania, Hobart, Tasmania 7001, \\ Australia \\ ${ }^{2}$ Antarctic Climate and Ecosystems Cooperative Research Centre, University of Tasmania, Hobart, Tasmania 7001, Australia \\ ${ }^{3}$ Bermuda Biological Station for Research, St George's GE01, Bermuda \\ ${ }^{4}$ Institute of Antarctic and Southern Ocean Studies, University of Tasmania, Hobart, Tasmania 7001, Australia \\ ${ }^{5}$ School of Earth, Ocean and Environmental Sciences and Plymouth Environmental Research Centre, University of Plymouth, \\ Plymouth PL4 8AA, United Kingdom
}

\begin{abstract}
A lab- and ship-based analytical intercomparison of two flow injection methods for the determination of iron in seawater was conducted, using three different sets of seawater samples collected from the Southern Ocean and South Atlantic. In one exercise, iron was determined in three different size-fractions $(<0.03 \mu \mathrm{m},<0.4 \mu \mathrm{m}$, and unfiltered) in an effort to better characterize the operational nature of each analytical technique with respect to filter size. Measured Fe concentrations were in the range 0.19 to $1.19 \mathrm{nM}$ using flow injection with luminol chemiluminescence detection (FI-CL), and 0.07 to $1.54 \mathrm{nM}$ using flow injection with catalytic spectrophotometric detection with $\mathrm{N}, \mathrm{N}$-dimethyl-p-phenylenediamine dihydrochloride (FI-DPD). The arithmetic mean for the FI-CL method was higher (by $0.09 \mathrm{nM}$ ) than the FI-DPD method for dissolved $(<0.4 \mu \mathrm{m}) \mathrm{Fe}$, a difference that is comparable to the analytical blanks, which were as high as $0.13 \mathrm{nM}$ (CL) and $0.09 \mathrm{nM}$ (DPD). There was generally good agreement between the FI-CL determinations for the $<0.03 \mu \mathrm{m}$ size fraction and the FI-DPD determinations for the $<0.4 \mu \mathrm{m}$ size fraction in freshly collected samples. Differences in total-dissolvable (unfiltered) Fe concentrations determined by the two FI methods were more variable, reflecting the added complexity associated with the analysis of partially digested particulate material in these samples. Overall, however, the FI-CL determinations were significantly $(P=0.05)$ lower than the FI-DPD determinations for the unfiltered samples. Our results suggest that the observed, systematic inter-method differences reflect measurement of different physicochemical fractions of Fe present in seawater, such that colloidal and/or organic iron species are better determined by the FI-CL method than the FI-DPD method. This idea is supported by our observation that inter-method differences were largest for freshly collected acidified seawater, which suggests extended storage (>6 months) of acidified samples as a possible protocol for the determination of dissolved iron in seawater.
\end{abstract}

It is now well established that iron regulates phytoplankton growth in large areas of the open ocean (Falkowski et al. 1998; Moore et al. 2002). As a result, there is now a pressing need for

\footnotetext{
*E-mail: Andrew.Bowie@utas.edu.au

\section{Acknowledgments}

The authors would like to thank the IRONAGES team for help with sampling the Atlantic Ocean standard seawater, the officers and crew of RSV Aurora Australis, and Ed Butler for internal review. The constructive comments of Robert $\mathrm{H}$. Byrne and two anonymous reviewers improved the manuscript. This work was supported by the Australian Research Council (X00106765 and DP0342826), the Antarctic Cooperative Research Centre, Australian National Antarctic Research Expeditions (ANARE), and the European Union (EVK2-CT-1999-00031).
}

reliable protocols for the measurement of low concentrations ( 100 pM) of Fe in open ocean seawater, including methods for sample collection, sample processing, and analytical determination (Coale et al. 1999). Only with such protocols in place will it be possible to distinguish between real environmental variability and methodological artifacts, and thus examine spatial and temporal trends in the oceanic distribution of this element. In the past decade, there has been a rapid development of new methods for the determination of Fe in seawater, and there are currently more than 10 in common use (Achterberg et al. 2001). It is of some concern that apparent differences in Fe concentrations obtained using these methods may simply reflect the differential determination of the various species of Fe present in seawater. Therefore, it is important to establish 


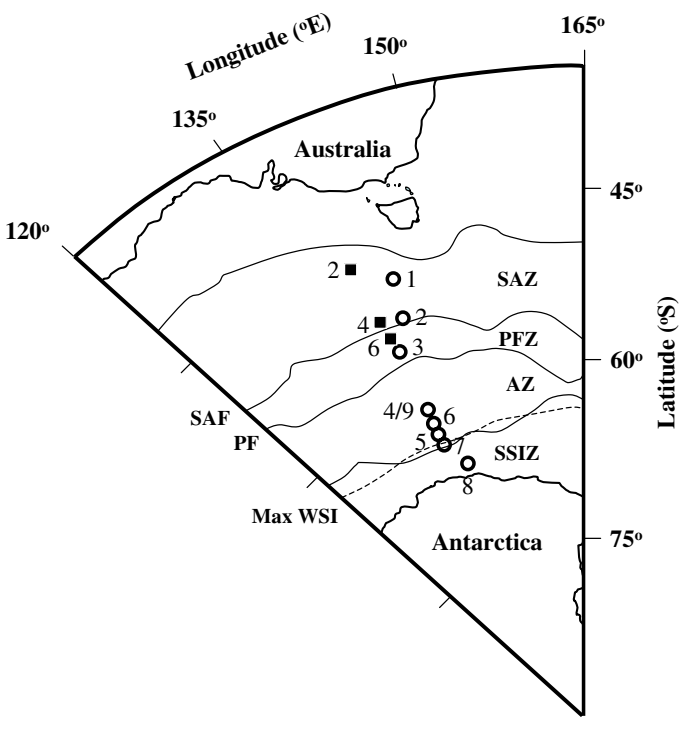

Fig. 1. Locations of sampling stations for the two Southern Ocean exercises. SAZ stations are shown as filled squares; CLIVAR-SR3 stations as hollow circles. Fronts and regions of relatively uniform water properties are shown; acronyms are given in Table 1. Max WSI is the maximum northward progression of winter sea ice.

the physical and chemical species of Fe (which may include different size fractions, two oxidation states, and a variety of organic and inorganic complexes) that are measured by different analytical methods. However, until very recently, there have been few rigorous intra- or inter-laboratory analytical comparisons for the measurement of Fe in seawater.

This article reports the results of a direct intercomparison of two published analytical methods for the determination of Fe in seawater at the subnanomolar concentrations typical of the remote open ocean. Parallel Fe determinations were made on replicate subsamples of seawater in three separate exercises, using (1) flow injection with chemiluminescence detection (FI-CL; hereafter referred to as CL) (Bowie et al. 1998) and (2) flow injection with catalytic spectrophotometry (FI-DPD; hereafter referred to as DPD) (Measures et al. 1995; Sedwick et al. 2000). In the first, laboratory-based exercise, archived acidified samples collected from the Southern Ocean during the March 1998 SAZ program (Sedwick et al. 1999) were analyzed for both dissolved Fe (dFe, $<0.4 \mu \mathrm{m}$ filtered) and total-dissolvable Fe (TDFe, unfiltered). In the second, laboratory-based exercise, dFe was determined in 10 individually bottled subsamples of the bulk IRONAGES standard material $(<0.2 \mu \mathrm{m}$ filtered), which was collected in the South Atlantic during October 2000 (Bowie et al. 2003). In the third exercise, performed at sea in November-December 2001, dFe $(<0.4 \mu \mathrm{m}$ filtered) and soluble Fe (sFe, $<0.03 \mu \mathrm{m}$ filtered) were determined in watercolumn samples collected at 9 stations along the Southern Ocean CLIVAR-SR3 section $\left(\sim 142^{\circ} \mathrm{E}\right)$, from several distinct oceanographic regions. The principal aims of these exercises were to directly compare $\mathrm{Fe}$ measurements using the same samples with two different FI methods, and to identify factors that may be responsible for operational differences between them. We envisage that this study will lead to the design of further analytical experiments to pinpoint the causes of differences between such methods.

\section{Materials and procedures}

Cleaning procedures-All plastic containers, filtering apparatus, and transfer tubing were rigorously cleaned by extended leaching in sub-boiling quartz-distilled hydrochloric acid (Q-HCl), liberally rinsed with deionized water (DIW, $>18 \mathrm{M} \Omega$-cm resistivity), and stored in clean zipper-seal polyethylene bags or plastic boxes. Polycarbonate water samplers used in the $S A Z$ and CLIVAR-SR3 programs were rinsed with DIW, soaked for 2 weeks in dilute aqueous Triton X-100 surfactant, and then soaked for 4 weeks in $\sim 1 \mathrm{M}$ Q- $\mathrm{HCl}$ or AR Select grade $\mathrm{HCl}$ (Mallinckrodt); all operations were performed within a class100 clean-air laboratory. The water samplers were thoroughly rinsed with DIW between each soaking step and stored wet in clean polyethylene bags before and during the cruises. The water samplers were rinsed with DIW after each shipboard deployment.

Low density polyethylene (Nalgene) sample bottles were soaked in $\sim 2 \%$ aqueous Decon detergent for $3 \mathrm{~d}$, then $\sim 2 \mathrm{M}$ Q-HCl for $3 \mathrm{~d}$, and finally conditioned over boiling $\sim 6 \mathrm{M} \mathrm{HCl}$ (AnalaR grade, Merck) fumes for $3 \mathrm{~d}$ (Tschopel et al. 1980), with 4 to 5 DIW rinses between each step. Caps were subjected to the same steps as the bottles, except that in the final stage they were soaked in $\sim 6 \mathrm{M} \mathrm{Q-HCl}$ for $3 \mathrm{~d}$. The bottles were filled with $\sim 0.5 \mathrm{M}$ Q-HCl and stored in clean plastic containers and were liberally rinsed with DIW and then sample water immediately before filling. Polycarbonate filter membranes (Poretics) were soaked for 2 weeks in $\sim 6 \mathrm{M} \mathrm{Q}-\mathrm{HCl}$, rinsed 5 times with DIW, and then stored in DIW. Cleaning procedures for the IRONAGES samples are detailed below.

Safety considerations-Concentrated $\mathrm{HCl}$ used for cleaning is corrosive, causes severe burns, and is irritating to the respiratory system. All procedures were performed in a wellventilated laboratory, with users wearing protective cleanroom clothing (coveralls, boots, shoes, and gloves) and safety glasses at all times.

Sample collection and processing - SAZ and CLIVAR-SR3 samples were collected from the Southern Ocean during voyages AU9806 (SAZ cruise) and AU0103 (CLIVAR-SR3 cruise) of RSV Aurora Australis. Station locations and acronyms for the major oceanographic features located along the meriodional section at $\sim 140^{\circ} \mathrm{E}-142^{\circ} \mathrm{E}$ are shown in Fig. 1 and Table 1 . We determined dFe and TDFe by both FI methods in samples from 3 stations from the $S A Z$ cruise (S2, S4, and S6: 6 depths for each). Dissolved Fe was determined by both FI methods in samples from 9 stations from the CLIVAR-SR3 cruise (C1 to C9: 3 to 6 depths at each); we also determined sFe at 8 CLIVAR-SR3 stations by the CL method. Samples from the upper water column (0 to $300 \mathrm{~m}$ depth) were collected by hydrocast in 6-L custom- 
Table 1. Trace metal station locations, oceanographic fronts, and regions occupied during the SAZ and CLIVAR-SR3 expeditions south of Australia

\begin{tabular}{llll}
\hline Station* & \multicolumn{1}{c}{ Location } & \multicolumn{1}{c}{ Region } \\
\hline S2 & $44.99^{\circ} \mathrm{S} 141.52^{\circ} \mathrm{E}$ & Acronym \\
$\mathrm{C} 1$ & $46.90^{\circ} \mathrm{S} 142.00^{\circ} \mathrm{E}$ & Subantarctic Zone & SAZ \\
$\mathrm{S} 4$ & $49.53^{\circ} \mathrm{S} 141.80^{\circ} \mathrm{E}$ & Subantarctic Zone & SAZ \\
$\mathrm{C} 2$ & $50.31^{\circ} \mathrm{S} 143.34^{\circ} \mathrm{E}$ & Northern edge of Subantarctic Front & SAF \\
S6 & $53.04^{\circ} \mathrm{S} 141.83^{\circ} \mathrm{E}$ & Subantarctic Front & SAF \\
$\mathrm{C} 3$ & $53.77^{\circ} \mathrm{S} 141.90^{\circ} \mathrm{E}$ & Polar Frontal Zone & $\mathrm{PFZ}$ \\
$\mathrm{C} 4 \dagger$ & $60.77^{\circ} \mathrm{S} 140.03^{\circ} \mathrm{E}$ & Polar Frontal Zone & $\mathrm{PFZ}$ \\
$\mathrm{C} 9 \dagger$ & $60.80^{\circ} \mathrm{S} 139.95^{\circ} \mathrm{E}$ & $\mathrm{AZ}$ \\
$\mathrm{C} 6$ & $61.34^{\circ} \mathrm{S} 139.81^{\circ} \mathrm{E}$ & Antarctic Zone & $\mathrm{AZ}$ \\
$\mathrm{C} 5$ & $62.31^{\circ} \mathrm{S} 139.90^{\circ} \mathrm{E}$ & Antarctic Zone & $\mathrm{AZ}$ \\
$\mathrm{C} 7$ & $63.76^{\circ} \mathrm{S} 140.06^{\circ} \mathrm{E}$ & Antarctic Zone & \\
$\mathrm{C} 8$ & $66.59^{\circ} \mathrm{S} 144.20^{\circ} \mathrm{E}$ & Seasonal Sea-Ice Zone & \\
\hline
\end{tabular}

*Stations are listed in order of increasing latitude. Station prefix " $\mathrm{S}$ " refers to the SAZ cruise and "C" refers to the CLIVAR-SR3 cruise.

$\dagger$ †tations C4 and C9 were re-occupations of the Southern Ocean Iron Release Experiment (SOIREE) site, $16 \mathrm{~d}$ apart

built polycarbonate water samplers suspended from a Superbraid nonmetallic line, using solid Teflon messengers and a 50-kg epoxy-coated steel end weight (Sedwick et al. 1997, 2000). To aid in the identification of contamination associated with any individual samplers, the samplers were deployed in the same order and at approximately the same depth for each hydrocast. Sample depths were estimated from the line-out read from a metering block and verified by comparison of measured sample salinities with salinity profiles from a conductivity-temperature-depth (CTD) sensor.

Upon recovery, the water samplers were transferred to a shipboard class-100 clean laboratory. Samplers were pressurized using $0.2 \mu \mathrm{m}$ filtered, high-purity nitrogen gas, and seawater subsamples were drawn through Teflon FEP tubing. Unfiltered subsamples for TDFe were collected first, followed by subsamples filtered through $0.4-\mu \mathrm{m}$ polycarbonate membranes. For 8 of the CLIVAR-SR3 stations, water samples were also filtered through $0.03-\mu \mathrm{m}$ polycarbonate membranes in an effort to differentiate between the "soluble-" $(<0.03 \mu \mathrm{m})$ and "colloidal-" $(0.03$ to $0.4 \mu \mathrm{m})$ sized Fe present in the "dissolved" $(<0.4 \mu \mathrm{m})$ Fe fraction. All subsamples were collected and stored in $60 \mathrm{~mL}$ low density polyethylene bottles. All transfer tubes, filtering apparatus, and sample containers were liberally rinsed with sample water before final collection of subsamples. Stringent trace metal clean protocols were followed at all times, with all sample manipulations performed under a class-100 laminar flow bench within the shipboard class-100 clean air laboratory.

All filtered subsamples were acidified with Seastar Baseline quartz-distilled concentrated hydrochloric acid $(31.2 \mu \mathrm{L}$ Q-HCl per 60 -mL sample; to $\mathrm{pH} \sim 2$ ) within $24 \mathrm{~h}$ of collection. Unfiltered samples were similarly acidified $(120 \mu \mathrm{L}$ Q-HCl per $60-\mathrm{mL}$ sample; to $\mathrm{pH}<2$ ). In this paper, Fe in the $<0.03 \mu \mathrm{m}$ size fraction is termed "soluble Fe" (sFe), Fe in the 0.03 to $0.4 \mu \mathrm{m}$ size fraction is termed "colloidal Fe" ( $\mathrm{cFe}$ ), and Fe in the $<0.4 \mu \mathrm{m}$ size fraction is termed "dissolved Fe" (dFe). Iron in the unfiltered, acidified fraction is termed "total-dissolvable Fe" (TDFe), which was determined after at least 6 months storage of the acidified samples, to allow for dissolution of particulate Fe.

IRONAGES samples were collected from the South Atlantic during cruise ANT XVIII/1 of R/V Polarstern in October 2000, as part of the IRONAGES program. For this cruise, a 1040-L high density polyethylene cubic tank (Eco Fut) was washed at the Royal Netherlands Institute for Sea Research using 1\% to $2 \%$ Decon solution followed by $\sim 20 \% \mathrm{HCl}$ (AnalaR, Merck) filled to the brim for 6 weeks. Prior to shipping, the tank was drained and thoroughly rinsed, and all taps and inlets securely sealed. The tank was also rinsed three times at sea using clean, unfiltered open-ocean seawater supplied from a towed-fish intake, using a trace metal clean peristaltic pumping system (Bowie et al. 2003). For each shipboard rinse, the added rinse seawater was acidified to $\mathrm{pH}<2$, mixed, and left for $2 \mathrm{~d}$ prior to draining.

The tank was next filled at $\sim 1.5$ to $1.8 \mathrm{~L} \mathrm{~min}^{-1}$ to approximately $700 \mathrm{~L}$ with seawater filtered through an in-line $0.2 \mu \mathrm{m}$ cellulose acetate membrane Sartobran-P polypropylene cartridge unit (Sartorius Ltd.), which had been thoroughly flushed with seawater prior to use. Sample water was acidified to $\mathrm{pH} \sim 2$ using $700 \mathrm{~mL}$ of $10 \mathrm{M} \mathrm{Q}-\mathrm{HCl}$ (quadruple sub-boiling quartz-distilled at the Royal Netherlands Institute for Sea Research) and the tank gently mixed by shaking. The seawater in the tank was pumped through Teflon FEP tubing leading directly from the tank into a laminar flow hood housed in a class-100 clean container. Subsamples were collected from the 1040-L tank in two hundred 1-L low density polyethylene bottles, which had been previously acid-cleaned at the University of Plymouth (Achterberg et al. 2001). A subset of these sample bottles were later shipped to 31 laboratories participating in the analytical intercalibration exercise overseen by SCOR/IUPAC Working Group 109 "Biogeochemistry 

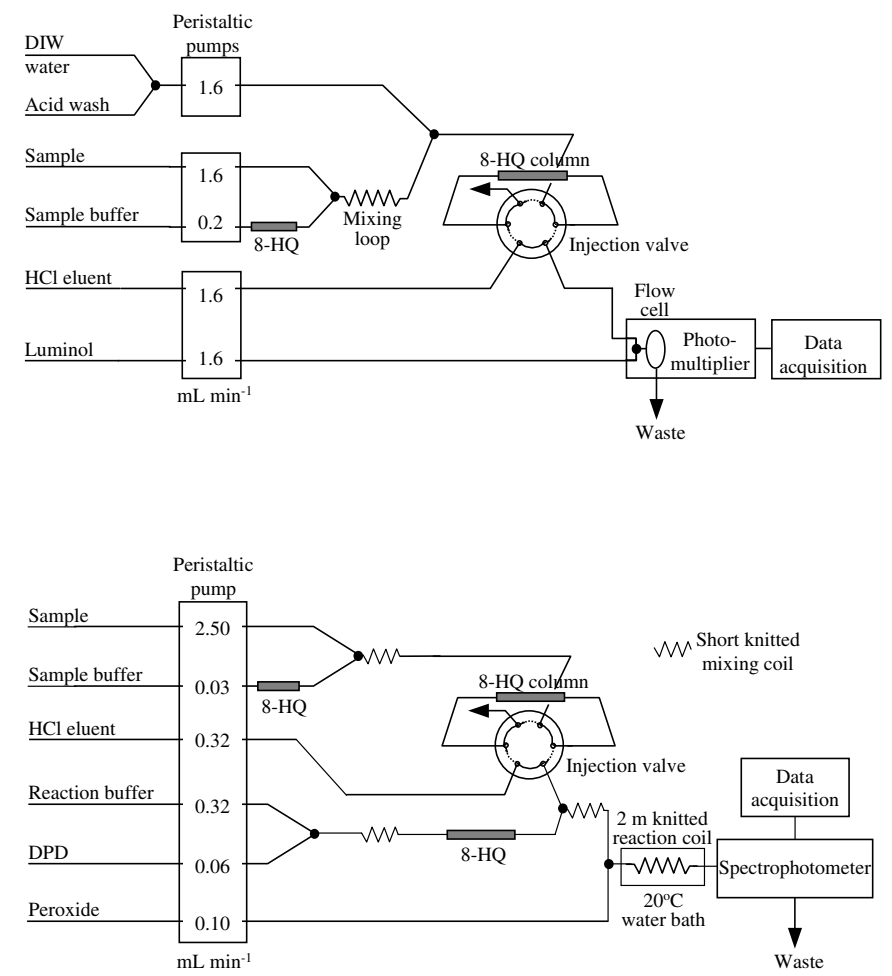

Fig. 2. The two flow injection manifolds used during this intercomparison study for the determination of $\mathrm{Fe}$ in seawater: (A) with chemiluminescence detection ( $C L$ method), and (B) with spectrophotometric detection (DPD method).

of Iron in Seawater" (Committee on Reference Materials for Ocean Science 2002). Another subset of samples is being used for storage, homogeneity, and stability studies at the University of Tasmania. For the intercomparison exercise reported here, a subset of 10 randomly selected individual IRONAGES sample bottles was used.

Analytical methods and instrumentation-Iron determinations were carried out in parallel on replicate samples using two FI methods, both of which have been extensively used in oceanographic studies (Sedwick and DiTullio 1997; Sedwick et al. 1997, 1999, 2000; Bowie et al. 2001, 2002a, 2002b, 2003). The first method was based on FI-CL (Bowie et al. 1998), using the effect of $\mathrm{Fe}(\mathrm{II})$ ions on the oxidation of luminol (5-amino-2,3-dihydro-1,4-phthalazinedione) to generate chemiluminescence, after sample reduction with sodium sulfite $\left(\mathrm{Na}_{2} \mathrm{SO}_{3}\right)$ for $>8 \mathrm{~h}$ (Fig. 2A). The second method was a modification (Sedwick at al. 2000) of the FI-spectrophotometric method described by Measures et al. (1995). The method relies on the ability of $\mathrm{Fe}(\mathrm{III})$ to catalyze the oxidation of $N, N$-dimethyl- $p$-phenylenediamine dihydrochloride (DPD) by hydrogen peroxide, with the assumption that Fe(II) is quantitatively oxidized to $\mathrm{Fe}(\mathrm{III})$ prior to the DPD oxidation step (Fig. 2B). Full operation details of the two FI manifolds are described in the original methods manuscripts (Bowie et al. 1998; Measures et al. 1995)

Both methods incorporate in-line analyte preconcentration using the chelating ligand 8-hydroxyquinoline (8HQ) immobilized on a chemically-resistant vinyl polymer resin (Toyopearl TSK), as developed by Landing et al. (1986). The CL method used Toyopearl TSK HW75F (fine) resin as the solid support resin (particle size: 30 to $60 \mu \mathrm{m}$; molecular weight range: 100,000 to $10,000,000$ for globular proteins) and packed the adsorbent material into a PTFE column, $10 \mathrm{~mm}$ long and $2.4 \mathrm{~mm}$ internal diameter. The DPD method used Toyopearl TSK HW40C (coarse) (particle size: 50 to $100 \mu \mathrm{m}$; molecular weight range: 100 to 7000 for globular proteins) and packed the adsorbent material into a PVC column, $5 \mathrm{~mm}$ long and $3.2 \mathrm{~mm}$ internal diameter.

The CL method was slightly modified from the original description in that it used improved, fully automated instrumentation based on a miniature, low power photon-counting head for CL detection (Hamamatsu Photonics model H6240-01), with system control, signal acquisition, and data processing controlled via a graphical programming environment (LabVIEW version 5.1, National Instruments Corp.), as described in Bowie et al. (2002b). A reducing agent $\left(\mathrm{Na}_{2} \mathrm{SO}_{3}, 100 \mu \mathrm{M}\right.$ final concentration) was also added to the $400 \mathrm{nM}$ Fe(II) working standard used for calibration. The DPD method closely followed the modifications to the Measures et al. (1995) method as detailed in Sedwick et al. (2000), using $\mathrm{HCl}$ in DIW as carrier solution rather than modified seawater.

\section{Assessment}

Our intercomparison exercises were designed to identify any consistent differences between results of two FI methods (CL and DPD) in seawater samples from several different open-ocean regions, for the determination of $\mathrm{Fe}$ in one or more size fractions (dissolved, total-dissolvable, and soluble). Analyses of the SAZ and IRONAGES samples were performed in Hobart after storage at room temperature for periods of approximately 3 y and 6 months, respectively. For each water-column profile or batch of samples, analyses were conducted in parallel by the two analytical methods under identical laboratory conditions. The CLIVAR-SR3 sample analyses (dFe only) were performed at sea within days of sample acidification, except for CL analysis of samples from stations C8 and C9, which took place in the Hobart laboratory. Ninetytwo samples were analyzed in total.

Calibration-Instruments were calibrated daily using standard curves derived from analysis of acidified low-Fe seawater samples to which small volumes of acidified Fe standard solution were added, with the concentration of the low-Fe seawater sample being determined by the method of standard additions. Standard curves were typically obtained using the lowest-Fe sample from each hydrocast station ( $S A Z$ and CLIVAR-SR3) or each batch of samples analyzed (IRONAGES). At the start of each set of analyses, a semi-quantitative survey 
Table 2. Analytical figures of merit*

\begin{tabular}{|c|c|c|c|c|c|c|c|}
\hline \multirow{2}{*}{$\begin{array}{l}\text { Exercise } \\
\text { Analytical method }\end{array}$} & & \multicolumn{2}{|c|}{$S A Z$} & \multicolumn{2}{|c|}{ CLIVAR-SR3 } & \multicolumn{2}{|c|}{ IRONAGES } \\
\hline & & $\mathrm{CL}$ & DPD & $\mathrm{CL}$ & DPD & $C L$ & DPD \\
\hline \multirow[t]{2}{*}{ Blank } & Range & 23 to 130 & 0 to 86 & 4 to 116 & 0 to 41 & 19 to 107 & 53 to 61 \\
\hline & Mean & $\begin{array}{l}39 \pm 29 \\
(n=13)\end{array}$ & $\begin{array}{l}35 \pm 24 \\
(n=14)\end{array}$ & $\begin{array}{l}45 \pm 25 \\
(n=9)\end{array}$ & $\begin{array}{c}26 \pm 14 \\
(n=8)\end{array}$ & $\begin{array}{l}49 \pm 35 \\
(n=5)\end{array}$ & $\begin{array}{l}57 \pm 6 \\
(n=2)\end{array}$ \\
\hline \multirow[t]{2}{*}{ Detection limit } & Range & 13 to 65 & 10 to $51 \dagger$ & 7 to 32 & 6 to $25 \dagger$ & 26 to 51 & 32 to 37 \\
\hline & Mean & $\begin{array}{l}49 \pm 17 \\
(n=14)\end{array}$ & $\begin{array}{l}24 \pm 12 \\
(n=12)\end{array}$ & $\begin{array}{l}19 \pm 9 \\
(n=9)\end{array}$ & $\begin{array}{l}18 \pm 6 \\
(n=7)\end{array}$ & $\begin{array}{c}37 \pm 11 \\
(n=5)\end{array}$ & $\begin{array}{l}34 \pm 4 \\
(n=2)\end{array}$ \\
\hline \multirow[t]{2}{*}{ FI precision, RSD (\%) $\ddagger$} & Range & 1.3 to 17.3 & $<20$ & 1.7 to 25.2 & $<20$ & 1.4 to 10.9 & $<20$ \\
\hline & Mean & $\begin{array}{l}7.0 \pm 4.4 \\
(n=36)\end{array}$ & 4.9 & $\begin{array}{c}11.6 \pm 6.4 \\
(n=47)\end{array}$ & ND§ & $\begin{array}{l}5.9 \pm 3.2 \\
(n=10)\end{array}$ & ND§ \\
\hline \multirow[t]{2}{*}{$\begin{array}{l}\text { Sensitivity } \\
\text { (calibration slope) }\end{array}$} & Range & $\begin{array}{l}405 \text { to } 872 \\
\mathrm{mV} \mathrm{nM}^{-1}\end{array}$ & $\begin{array}{c}60.7 \text { to } 136.9 \\
\mathrm{AU} \mathrm{nM}^{-1}\end{array}$ & $\begin{array}{l}237 \text { to } 958 \\
\mathrm{mV} \mathrm{nM}^{-1}\end{array}$ & $\begin{array}{c}76.9 \text { to } 174.9 \\
\mathrm{AU} \mathrm{nM}\end{array}$ & $\begin{array}{c}628 \text { to } 1053 \\
\mathrm{mV} \mathrm{nM}^{-1}\end{array}$ & $\begin{array}{l}41.1 \text { to } 67.2 \\
\mathrm{AU} \mathrm{nM}^{-1}\end{array}$ \\
\hline & Mean & $\begin{array}{c}705 \pm 155 \\
(n=13)\end{array}$ & $\begin{array}{l}100 \pm 21 \\
(n=17)\end{array}$ & $\begin{array}{c}633 \pm 246 \\
(n=9)\end{array}$ & $\begin{array}{c}120 \pm 36 \\
(n=7)\end{array}$ & $\begin{array}{c}830 \pm 180 \\
(n=5)\end{array}$ & $\begin{array}{l}59 \pm 9 \\
(n=6)\end{array}$ \\
\hline
\end{tabular}

*All data given in pM (unless otherwise stated). Error bounds indicate \pm one standard deviation. The range and mean represent all data gathered during each exercise.

$\dagger$ †etection limit has not been calculated for analyses where zero-loading blank $=0$

$\ddagger$ Repeatability between replicate FI measurements of peak height (CL method) and peak area (DPD method)

$\S N D=$ not determined

was performed to rank samples in terms of Fe concentration; the samples were then analyzed in order of increasing Fe concentration, with the lowest Fe sample being used for the standard curve. Standard additions were typically in the range 0.1 to $0.8 \mathrm{nM}$ for the $S A Z$ and CLIVAR-SR3 samples and 0.5 to $2.0 \mathrm{nM}$ for the IRONAGES samples. Results were calculated from peak heights for the CL method and peak areas for the DPD method. Iron standards were prepared by serial dilution of a $0.02 \mathrm{M}\left(\mathrm{NH}_{4}\right)_{2} \mathrm{Fe}\left(\mathrm{SO}_{4}\right)_{2} \cdot 6 \mathrm{H}_{2} \mathrm{O}$ (Merck) solution in $0.1 \mathrm{M} \mathrm{Q}-\mathrm{HCl}$ for the CL method, and dilution of a $1000 \mathrm{mg} \mathrm{L}^{-1} \mathrm{Fe}(\mathrm{III})$ atomic absorption standard (Spectrosol, Merck) in 1\% Q-HCl for the DPD method. Replicate analyses $(n=3$ for CL and $n=2$ for DPD) were performed for all sample and standard solutions. The time for one analytical cycle was approximately 3 min and 5 min for the CL and DPD methods, respectively.

Blanks-Analytical blanks were defined in a manner consistent with previous oceanographic studies that have made use of these methods (e.g., Sedwick et al. 2000; Bowie et al. 2001). For the CL method, the blank signal was defined as the signal obtained from a 1-min loading of sample buffer only (ammonium acetate) onto the $8 \mathrm{HQ}$ column followed by a routine 40s DIW rinse, plus that due to the addition of $100 \mu \mathrm{M}$ sodium sulfite. The latter was obtained by double spiking a low-Fe concentration sample and was found to be negligible $(<3 \mathrm{pM}$ $\mathrm{Fe}$ ) for the CLIVAR-SR3 exercise. For the DPD method, there is a blank signal due to the effect of the seawater matrix on the flow stream absorbance ("zero-loading blank"), which is typically $<20 \%$ of sample absorbance. For each analysis, this zeroloading blank (in absorbance units) was estimated from extrapolation of sample absorbance versus $8 \mathrm{HQ}$ column loading time to a load time of zero, using a low-Fe sample. For each analysis, the absorbance value of the zero-loading blank was converted to an Fe concentration using the most appropriate calibration curve. The DPD method also has a potential blank associated with the in-line addition of ammonium acetate buffer solution to the sample; however, the Fe added with the buffer, as estimated from the analysis of DIW with multiple additions of buffer solution using the method of standard additions, was found to be negligible.

There is also a procedural blank for all acidified samples due to the Fe content of the Seastar Baseline Q-HCl used for sample acidification. This blank contribution was estimated by analysis of DIW containing multiple additions of acid, using the method of standard additions. These acid blank values amounted to $65 \mathrm{pM}$ (measured by the DPD method) for the $S A Z$ dFe samples, and $14 \mathrm{pM}$ (CL method) and $33 \mathrm{pM}$ (DPD method) for the CLIVAR-SR3 samples. The acid blank was not determined for the IRONAGES samples. Because all samples are considered here for the purposes of intercomparison only (rather than oceanographic study), we have chosen to ignore the acid blank associated with sample acidification (i.e., the acid blank has not been subtracted from the measured sample concentrations presented here).

Detection limits-For the CL method, the detection limit was defined as the analyte concentration corresponding to a signal of three times the standard deviation on replicate analyses of the blank $(n=4)$. For the DPD method, the detection limit was defined as the analyte concentration corresponding to an absorbance signal that is three standard deviations above the zero-loading blank, where $20 \%$ is used as a typical maximum value of relative standard deviation on peak area for replicate analyses of a low-Fe seawater sample (Sedwick et al. 2000). 


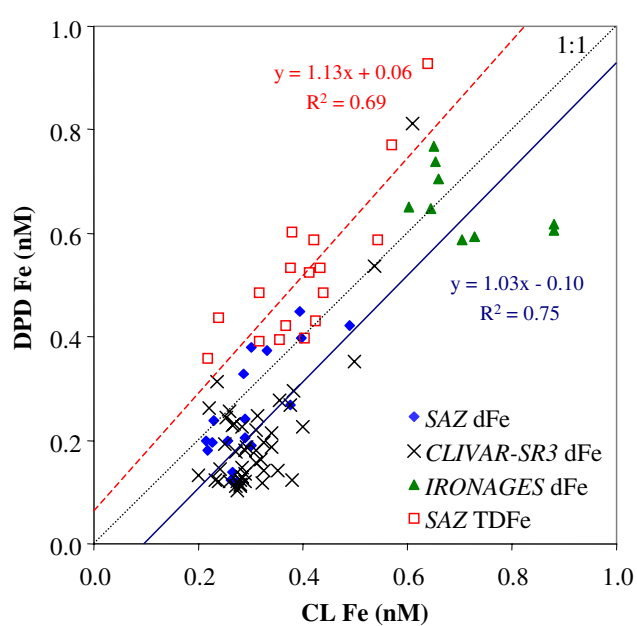

Fig. 3. Plot of DPD Fe concentration versus $C L$ Fe concentration for all three exercises. The dFe regression line (SAZ, CLIVAR-SR3, and IRONAGES exercises, solid line), TDFe regression line ( $S A Z$ exercise only, dashed line), and 1:1 line (dotted line) are shown. Possible contaminated samples (see legends to Figs. 4 to 6 ) are not included.

Analytical figures of merit-The analytical figures of merit for the two FI methods (Table 2) used in this study were rigorously determined during the lab-based $S A Z$ and IRONAGES intercomparison exercises. Essentially identical methods were used at sea for the CLIVAR-SR3 intercomparison exercise. When considering the mean data for all three intercomparison exercises, analytical blanks were in the range 39 to $49 \mathrm{pM}$ for CL method and 26 to $57 \mathrm{pM}$ for the DPD method. Relative standard deviations on replicate FI measurements of peak height (CL method) and peak area (DPD method) were $<12 \%$ and $<20 \%$, respectively, which yields detection limits of 19 to $49 \mathrm{pM}$ for the CL method and 18 to $34 \mathrm{pM}$ for the DPD method. These detection limits are roughly an order of magnitude lower than the dissolved Fe concentrations found in the SAZ, CLIVAR-SR3, and IRONAGES samples, as reported below. Overall analytical uncertainties for the two methods, based on 8 separate determinations of a low-Fe composite, filtered, acidified seawater sample, were $14.9 \%$ and $7.4 \%$ for the CL and DPD methods, respectively. Correlation coefficients $\left(r^{2}\right)$ were better than 0.98 (and typically $>0.99$ ) for all calibration curves. The figures of merit for the two FI methods were not notably different.

Overview of the entire data set-Fig. 3 shows a plot of DPD Fe concentration versus $\mathrm{CL}$ Fe concentration for the pooled dataset from all three intercomparison exercises, with CL Fe assigned to the $\mathrm{x}$-axis. A single linear regression fit through all the dFe data (solid blue line, Fig. 3) indicates that there is a small absolute bias between the two methods (positive $\mathrm{x}$-axis intercept), suggesting that dFe concentrations measured by the CL method tend to be $0.1 \mathrm{nM}$ higher than DPD method concentrations; there is no significant systematic bias with respect to dFe concentration (slope close to unity). Conversely, a single linear regression fit through all the TDFe data (dashed red line, Fig. 3) indicates that there is also an absolute bias between the two methods (positive y-axis intercept), but suggesting that TDFe concentrations measured by the DPD method tend to be $0.06 \mathrm{nM}$ higher than CL concentrations; there is also a proportional systematic bias with respect to TDFe concentration (slope equal to 1.13). Regression coefficients are 0.75 for dFe and 0.69 for TDFe. The data tend to cluster along trends that differ between exercises and between measured fractions (i.e., dFe vs TDFe). This shows that the $S A Z$ dFe and IRONAGES dFe data scatter reasonably close to the 1:1 line, bearing in mind the analytical uncertainties of both methods (shown on Figs. 4 and 5). In contrast, the CLIVAR-SR3 dFe data define a trend where CL dFe concentrations are consistently higher than DPD dFe concentrations. The converse is true for the SAZ TDFe data, for which DPD concentrations are higher than corresponding CL values.

Despite apparent systematic differences in the Fe concentrations measured by the two methods, the observed consistency in the shape of the vertical profiles suggests that both methods are able to resolve small differences in concentration at these low Fe levels ( $<0.4 \mathrm{nM}$ dFe); e.g., see profiles for stations S4 and C7 in Figs. 4 and 5. The results of each intercomparison exercise are discussed separately below.

SAZ intercomparison-Results for the lab-based intercomparison on the 3-y archived samples from the $1998 S A Z$ cruise show reasonably good agreement between CL and DPD methods, especially for vertical profiles of dissolved $(<0.4 \mu \mathrm{m}) \mathrm{Fe}$ (Fig. 4). The CL method generally measured similar to higher dFe concentrations than the DPD method, although the difference between methods varied with sampling location (Fig. 4). At station S2 (Subantarctic Zone; Table 1), CL measured 57\% more dFe than DPD (mean of offsets between corresponding samples in vertical profile), whereas the mean offset was only $16 \%$ at station S6 (Polar Frontal Zone), and the difference between the CL and DPD dFe values was insignificant at station S4 (northern edge of Subantarctic Front) (see Statistical analysis). Interestingly, the opposite was true for vertical profiles of TDFe, with the DPD method generally measuring higher concentrations than CL, with mean offsets of 35\%, $28 \%$ and 7\% for stations S2, S4, and S6, respectively. There was no significant difference in the magnitude of the offsets for mixedlayer versus sub-thermocline samples, for both dFe and TDFe.

CLIVAR-SR3 intercomparison-Results for the shipboard intercomparison for freshly collected samples ( $<2$ weeks old) from the 2001 CLIVAR-SR3 cruise show a similar trend to the $S A Z$ profiles, with CL generally measuring higher dFe $(<0.4 \mu \mathrm{m})$ concentrations than DPD (Fig. 5). Analytical differences were more pronounced than for the $S A Z$ intercomparison exercise (compare SAZ and CLIVAR-SR3 data in Fig. 3) for all but one sampling location, station $\mathrm{C} 1$ (Subantarctic Zone), where the DPD method measured dFe concentrations 0.01 to $0.08 \mathrm{nM}$ (mean offset 16\%) greater than CL. For the stations where the CL method measured higher dFe concentrations than the DPD method, the mean of offsets between corresponding samples 

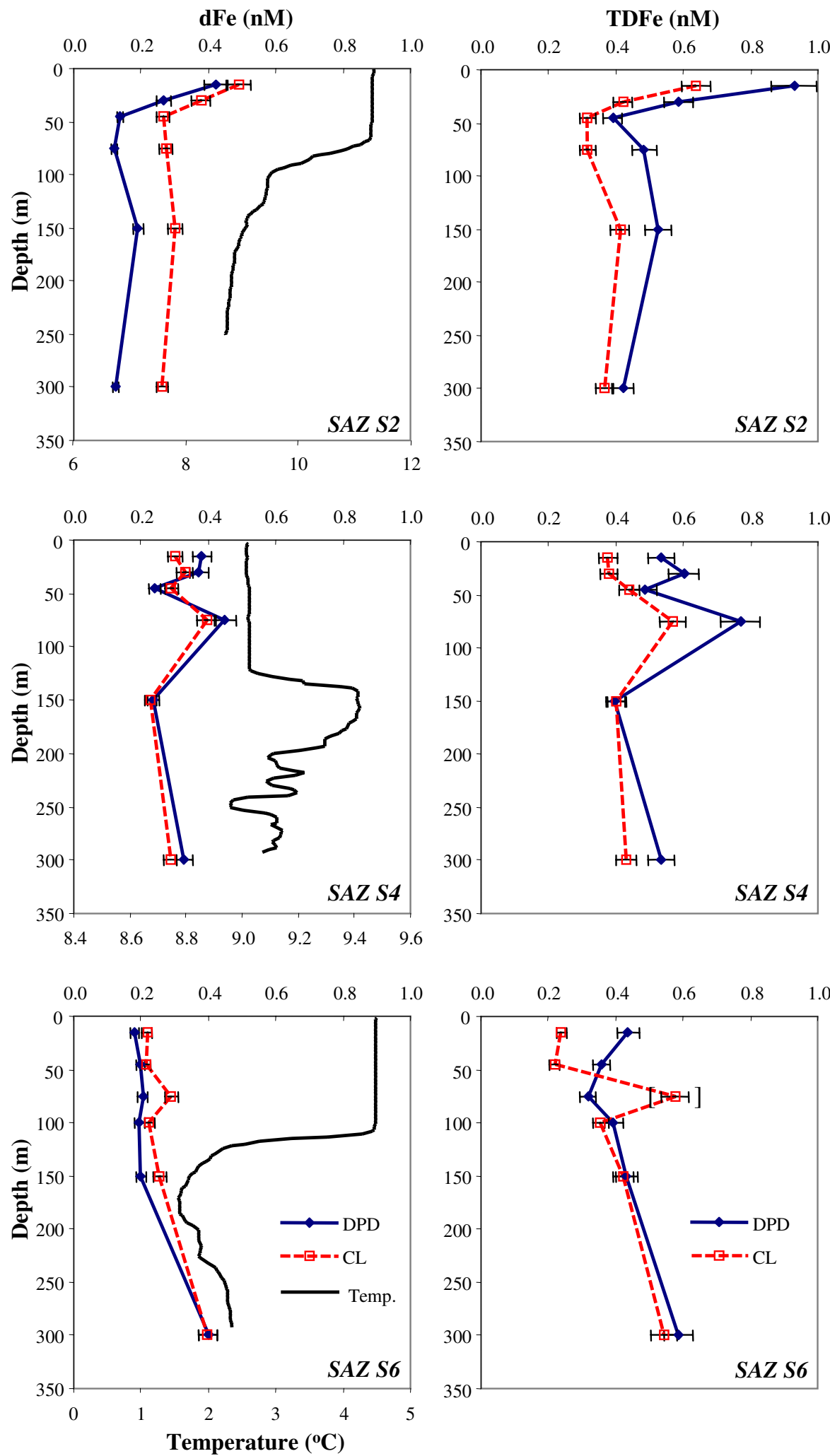

Fig. 4. Comparison of $C L$ and DPD methods for dFe and TDFe in samples taken at three stations during the 1998 SAZ cruise. Temperature data are shown alongside dFe profiles. Station locations are given in Table 1 and Fig. 1. Error bars are based on the average precision for each method for this exercise (7.0\% for $\mathrm{CL}$ and $7.4 \%$ for DPD). Points in square brackets indicate possible sample contamination. 

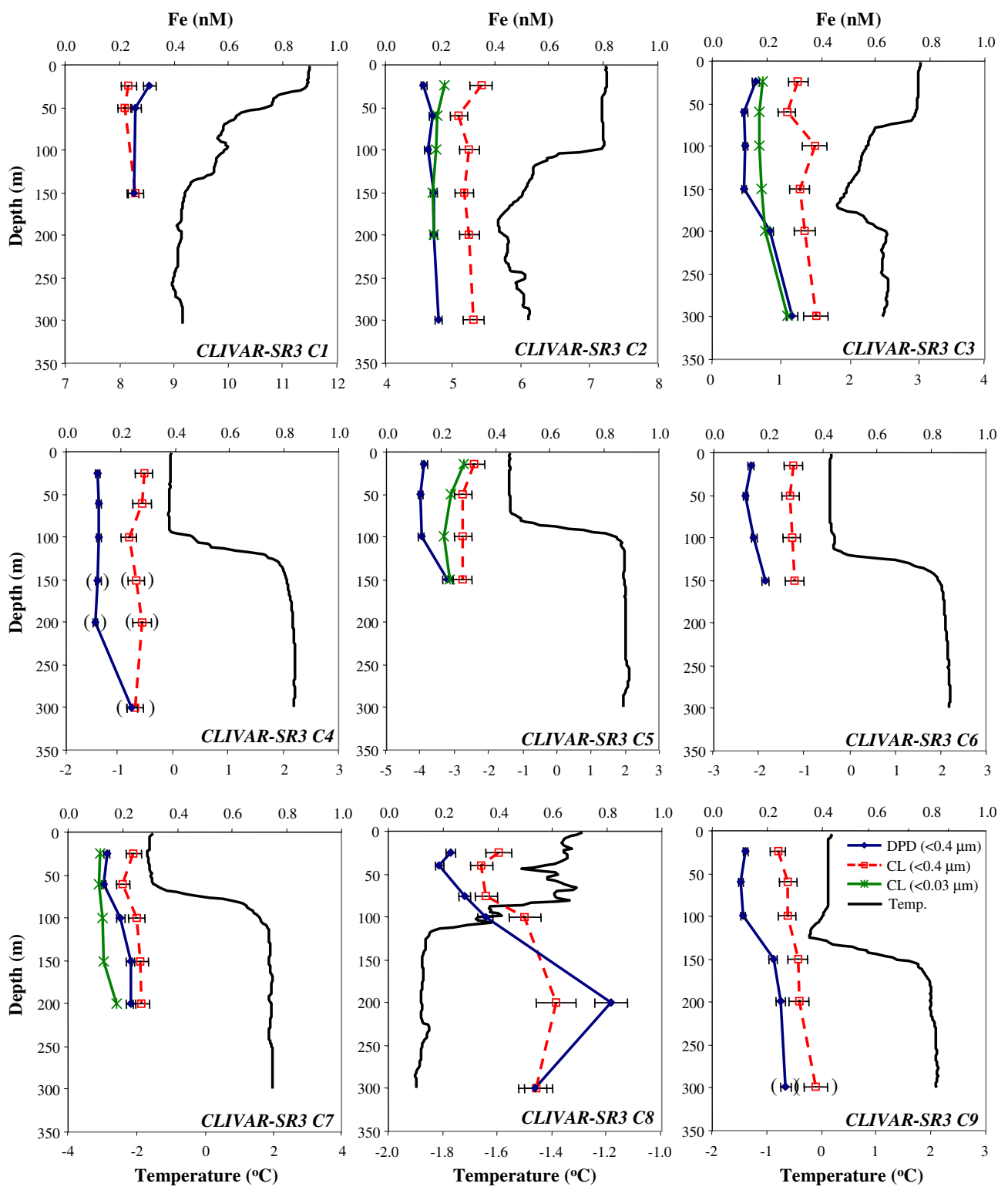

Fig. 5. Comparison of $C L$ and DPD methods for dFe and sFe (CL only) in samples taken at 9 stations during the 2001 CLIVAR-SR3 cruise. Temperature data are shown. Station locations are given in Table 1 and Fig. 1. Error bars (shown on dFe profiles only) are based on the average precision for each method for this exercise (11.6\% for CL and $7.4 \%$ for DPD). Points in curved brackets indicate possible pre-trip of sample bottles (i.e., depth uncertainty).

varied from $15 \%$ at station C8 (Mertz Glacier Polynya) to $191 \%$ at station C3 (in the Polar Frontal Zone). The dFe concentrations through the water column at the continental shelf station C8 (0.19 to $0.81 \mathrm{nM})$ were generally higher than the other CLIVAR-SR3 stations. In addition, for this intercomparison exercise, there was evidence of a difference in the analytical offset between mixed-layer and sub-thermocline samples, with the greatest offset between methods (CL > DPD) observed in the upper mixed layer. This is particularly pronounced for stations $\mathrm{C} 3, \mathrm{C} 5$, and $\mathrm{C} 6$ to $\mathrm{C} 9$, where the DPD dFe profiles demonstrate a nutrient-like structure, with dFe depleted in the mixed layer above a ferricline (increase in dFe concentrations) over the 100- to 300-m depth range. For these stations, the CL dFe profiles show a more uniform vertical structure.

sFe $(<0.03 \mu \mathrm{m})$ was also measured by CL at 8 of the CLIVAR$S R 3$ stations. These sFe data will be discussed more fully elsewhere (Bowie et al. in prep. unref.). Fig. 5 shows the sFe profiles for four representative stations (C2, C3, C5, and C7). For most stations, the CL sFe profiles are similar to the DPD dFe profiles, whereas the CL dFe concentrations were significantly 


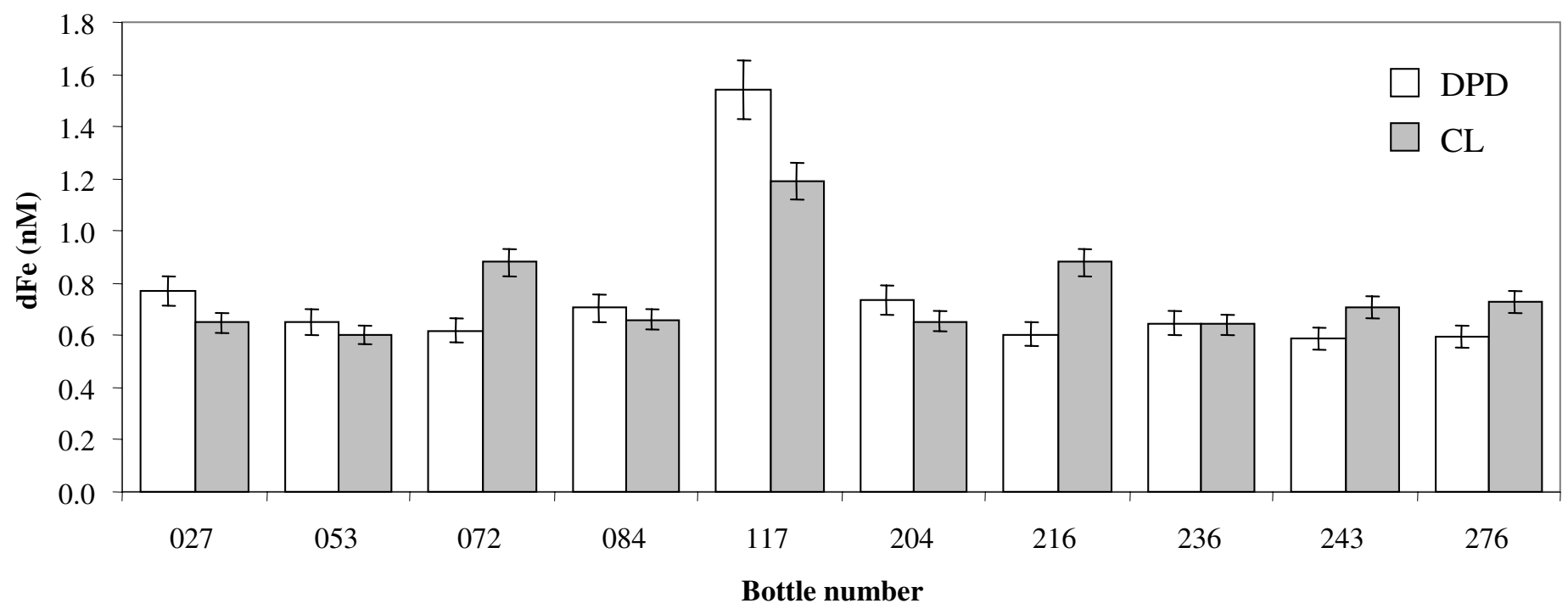

Fig. 6. Comparison of $\mathrm{CL}$ and DPD methods for 10 randomly selected bottles of the IRONAGES standard material collected from the South Atlantic Ocean in 2000. Error bars are based on the average precision for each method for this exercise (5.9\% for CL and 7.4\% for DPD). Sample bottle 117 was contaminated (see text).

higher than the corresponding DPD values. For example, at station C2, CL dFe concentrations $(0.31 \pm 0.03 \mathrm{nM})$ were nearly double the DPD dFe concentrations $(0.17 \pm 0.02 \mathrm{nM})$, but CL sFe concentrations $(0.19 \pm 0.02 \mathrm{nM})$ were similar to the $\mathrm{DPD} \mathrm{dFe}$ concentrations. In this regard, we note that operationally defined measurements of "dissolved" Fe may include colloidal Fe (cFe) in the $<0.4 \mu \mathrm{m}$ size range, as well as truly soluble species (Wu et al. 2001). However, CL sFe and DPD dFe values were not similar for all stations; for stations C5 (Fig. 5) and C6 (sFe data not shown), located at the northern extent of the Seasonal Sea Ice Zone, CL sFe concentrations were similar to CL dFe concentrations and significantly higher than DPD dFe concentrations.

IRONAGES intercomparison-Results from the lab-based intercomparison on 10 individually bottled subsamples of the IRONAGES standard seawater, which had been stored for $\sim 6$ months, showed excellent agreement between the two analytical methods. Mean dFe concentrations of $0.76 \pm 0.18 \mathrm{nM}$ and $0.75 \pm 0.29 \mathrm{nM}(n=10)$ were obtained using the CL and DPD methods, respectively (Fig. 6). Both methods measured significantly higher dFe concentrations for subsample bottle bottle 117 ( $Q$-test, $P=0.05$ ), which we assume was contaminated. However, the data for this outlier sample are included in this report, because they are still useful for the purposes of intercomparison. Additional laboratory experiments (Bowie unpubl. data unref.) have demonstrated that the IRONAGES standard seawater was homogeneous, in that there were no significant differences (paired two-tailed $t$ test, $P=0.05$ ) between $\mathrm{dFe}$ concentrations for different subsample bottles, nor was there any correlation between dFe concentrations and bottle sequence.

Statistical analysis-To assess the statistical significance of differences in measured concentrations, paired twotailed $t$ tests were applied to the results of each of the three intercomparison exercises and of each vertical concentration profile for the $S A Z$ and CLIVAR-SR3 exercises. Measured dFe concentrations varied over the ranges 0.12 to $0.93 \mathrm{nM}(S A Z)$, 0.11 to $0.81 \mathrm{nM}$ (CLIVAR-SR3), and 0.59 to $1.54 \mathrm{nM}$ (IRONAGES). We assume that the data from each method are normally distributed, that the precision and bias of each method is constant over the range of values above, and that any errors, either random or systematic, are independent of concentration. Results of this $t$ test in comparing concentrations for corresponding samples from the SAZ and CLIVAR-SR3 exercises (Table 3 ) indicate that $\mathrm{dFe}$ and TDFe concentrations measured by the CL method were significantly different from those measured by the DPD method for the pooled dataset at the 95\% confidence level $(P=0.05)$. Application of the $t$ test to individual station profiles for the SAZ and CLIVAR-SR3 exercises shows that there was no significant difference between concentrations measured by the CL and DPD methods for dFe at stations S4, C1, and C8, and for TDFe at station S6. In addition, the CL sFe concentrations were not significantly different from corresponding DPD dFe concentrations, except for the profile at station C7. For all other profiles, the CL dFe results were significantly different from the DPD dFe concentrations. There were no significant differences $(P=0.05)$ between the CL and DPD dFe concentrations for 
Table 3. Results from two-tailed $t$ tests for $C L$ versus DPD on related sets of paired data for each exercise and for each profile, at the $95 \%$ confidence level $(P=0.05)$.

\begin{tabular}{|c|c|c|c|c|}
\hline Exercise & Profile & $d f^{*}$ & $t$ (critical) & $t$ (experimental) $\dagger$ \\
\hline \multirow[t]{4}{*}{$S A Z \mathrm{dFe}$} & All 3 stations (pooled) & 17 & 2.11 & 2.53 \\
\hline & $\mathrm{S} 2$ & 5 & 2.57 & 9.67 \\
\hline & S4 & 5 & 2.57 & -1.57 \\
\hline & S6 & 5 & 2.57 & 3.01 \\
\hline \multirow[t]{4}{*}{ SAZ TDFe } & All 3 stations (pooled) & 17 & 2.11 & -3.44 \\
\hline & s2 & 5 & 2.57 & -4.12 \\
\hline & S4 & 5 & 2.57 & -3.31 \\
\hline & S6 & 5 & 2.57 & -0.44 \\
\hline CLIVAR-SR3 & All 9 stations (pooled) & 45 & 2.01 & 8.98 \\
\hline dFe: $(0.4 \mu \mathrm{m} \mathrm{CL}$ & $\mathrm{C} 1$ & 2 & 4.30 & -1.60 \\
\hline \multirow[t]{8}{*}{ vs $0.4 \mu \mathrm{m}$ DPD) } & $\mathrm{C} 2$ & 5 & 2.57 & 8.26 \\
\hline & $\mathrm{C} 3$ & 5 & 2.57 & 6.81 \\
\hline & $\mathrm{C} 4$ & 5 & 2.57 & 5.04 \\
\hline & $\mathrm{C} 5$ & 3 & 3.18 & 4.94 \\
\hline & $\mathrm{C} 6$ & 3 & 3.18 & 11.10 \\
\hline & $\mathrm{C7}$ & 4 & 2.78 & 5.27 \\
\hline & $\mathrm{C} 8$ & 5 & 2.57 & 1.01 \\
\hline & C9 & 5 & 2.57 & 7.26 \\
\hline CLIVAR-SR3 & All 4 stations (pooled) & 19 & 2.09 & 1.39 \\
\hline size-fractionated Fe: & $\mathrm{C} 2$ & 4 & 2.78 & 1.57 \\
\hline \multirow[t]{3}{*}{ (0.03 $\mu \mathrm{m}$ CL vs. $0.4 \mu \mathrm{m}$ DPD) } & $\mathrm{C} 3$ & 5 & 2.57 & 1.83 \\
\hline & C5 & 3 & 3.18 & 3.00 \\
\hline & $\mathrm{C} 7$ & 4 & 2.78 & -3.63 \\
\hline \multirow[t]{2}{*}{ IRONAGES } & All samples (pooled) & 9 & 2.26 & 0.24 \\
\hline & Excluding bottle 117 & 8 & 2.31 & 1.11 \\
\hline
\end{tabular}

*df is the number of degrees of freedom.

$\dagger$ A negative value indicates DPD $>C L$

the IRONAGES samples. The difference between Fe concentrations measured in the same samples by the two analytical methods may be the result of a number of factors that are discussed below.

Sample contamination or loss of analyte-Low-level contamination of the samples or analyte "loss" (e.g., resulting from Fe precipitation or container adsorption) might have occurred during collection or processing. However, given that almost identical methods of sampling, filtration, and storage were used for all three exercises, such contamination or analyte loss could only have occurred during the final subsampling, immediately prior to analysis. We consider it unlikely that such contamination or analyte loss caused the significant systematic concentration offsets that we observed between methods.

System calibration-Each FI method was calibrated using at least one separate standard curve for each station profile ( $S A Z$ and CLIVAR-SR3 exercises) or batch of samples (IRONAGES exercise), as well as for each size fraction (sFe, dFe, TDFe), typically using additions of standard to the sample with lowest Fe concentration. Changes in the sensitivities of both FI systems may be the result of differences in sample matrix, reagent age, or laboratory temperature. Given that the SAZ and IRONAGES analyses were conducted in parallel, under identical labora- tory conditions, with freshly prepared reagents, we presume that observed sensitivity changes reflect differences in sample matrix or perhaps $\mathrm{pH}$, rather than effects of temperature on detector efficiency, or of reagent age on reaction chemistry. We conclude that variations in analytical sensitivity are unlikely to explain the generally consistent and systematic differences between CL and DPD determinations.

Quantification of analytical blank-Our results suggest that overestimation or underestimation of the analytical blank by one or both methods cannot account for the observed differences between methods, because (1) analytical blank signals were generally small $(<20 \%)$ in relation to sample signals (Table 2); (2) for the $S A Z$ exercise, CL dFe concentrations were higher than DPD dFe concentrations, whereas CL TDFe concentrations were lower than DPD TDFe concentrations (although blanks were defined in the same manner for both dFe and TDFe determinations); and (3) for CLIVAR-SR3 stations C3 to C9 (excluding station C4 for which sample depths are uncertain), the offset between CL dFe and DPD dFe concentrations is greatest at shallow depths, with dFe concentrations tending to converge in the 100- to 300-m depth range.

Potential interferences-To explain our observed intermethod differences, a chemical interference to the CL deter- 
mination of Fe would need to (1) be present at a greater concentration in surface waters relative to deep waters, (2) have concentration vary significantly with sampling location, and (3) have a greater effect on the determination of dFe compared with TDFe (i.e., be present predominantly in dissolved form).

The luminol CL method, in the presence of $\mathrm{O}_{2}$ and without added $\mathrm{H}_{2} \mathrm{O}_{2}$, is relatively insensitive to chemical interferents, including most trace metals (Seitz and Hercules 1972; Klopf and Nieman 1983; Rose and Waite 2001). Although Co(II) interferes with the CL analysis at the $1.0 \mathrm{nM}$ level (Bowie et al. 1998), the Co concentration in Southern Ocean surface waters is likely below $0.1 \mathrm{nM}$ (e.g., Martin et al. 1990). In additional experiments conducted during our intercomparison exercises using a composite sample from station $\mathrm{C} 2(\mathrm{dFe}=0.30 \pm 0.03 \mathrm{nM})$, addition of $0.2 \mathrm{nM} \mathrm{Co}(\mathrm{II})$ caused no interference to the $\mathrm{CL}$ method, whereas addition of $0.5 \mathrm{nM} \mathrm{Co}(\mathrm{II})$ resulted in a 33\% signal increase. Manganese is another potential interferent that could explain the greater difference between CL and DPD results for station $\mathrm{S} 2$ in the $S A Z$ exercise, because dissolved Mn has been observed to increase from $<0.2 \mathrm{nM}$ to $\sim 0.4 \mathrm{nM}$ between the Polar Front and the northern Subantarctic Zone south of Australia (Sedwick et al. 1997). However, additional experiments indicated that $10 \mathrm{nM}$ added $\mathrm{Mn}$ (II) did not interfere with Fe determination by the CL method.

For the DPD method, Measures et al. (1995) reported that $\mathrm{Cu}$ was the only trace metal likely to interfere with the determination of Fe in seawater, giving a positive signal at $\mathrm{Cu}$ concentrations >160 nM (Hirayama and Unohara 1988). However, $\mathrm{Cu}$ is present at concentrations of $\sim 1 \mathrm{nM}$ in Southern Ocean surface waters (Frew et al. 2001) and, for the DPD method as used in this study, Cu interference is masked by triethylenetetramine in the sample buffer (Measures et al. 1995).

Based on these considerations, we conclude that the observed differences between the CL and DPD Fe measurements are unlikely to result from chemical interferences to either method.

Analyte extraction and preconcentration-Although the same type of chelating ligand (8HQ) and solid support resin were used for the preconcentration columns in both methods, the resins were of different bead size, porosity, texture, and age, and the contact time between sample and $8 \mathrm{HQ}$ varied due to different sample flow rates (Fig. 2). These factors are likely to influence the extraction efficiency of the resin columns, and the speciation of Fe during the extraction step, thus the ability of each method to separate colloidal and/or ligand-bound Fe from the sample solution. Calculations using conditional stability constants for Fe complexes found in seawater suggest that there will be significant competition between natural ligands and $8 \mathrm{HQ}$ for Fe, which may affect the recovery of $\mathrm{Fe}(\mathrm{III})$ from seawater (Bowie et al. 2003). These considerations are consistent with our intercomparison results from the CLIVAR$S R 3$ exercise, which show a greater offset between CL and DPD $\mathrm{dFe}$ concentrations in the upper mixed layer, where the concentrations of Fe-binding organic ligands are possibly higher
(Rue and Bruland 1995). Thus it is conceivable that the CL method (after sample reduction using sulfite) is better able to separate and subsequently determine organically-bound Fe species than the DPD method.

Physicochemical speciation of Fe-For the CLIVAR-SR3 exercise, we observed a generally good agreement between the DPD dFe $(<0.4 \mu \mathrm{m})$ measurements and the CL sFe $(<0.03$ $\mu \mathrm{m})$ measurements. Noting this, we suggest that the sulfite reduction step in the CL method may render some of the colloidal Fe (0.03 to $0.4 \mu \mathrm{m}$ size range) available for separation and subsequent determination, perhaps through reduction of dissolved Fe(III) species, thus favoring the dissolution of colloidal Fe(III) species. Bruland and Rue (2001) reported that acidification to $\mathrm{pH} 1.7$ to 2.0 and storage of up to 1 month was necessary to solubilize colloidal Fe species and liberate organically bound Fe in filtered seawater samples. Thus for our Southern Ocean dFe samples that were acidified to $\mathrm{pH} 2.3$, we might expect significant concentrations of colloidal Fe, much of which may be bound to organic ligands (Wu et al. 2001).

For the $S A Z$ exercise, there is no obvious explanation for the higher TDFe concentrations measured by the DPD method in the unfiltered acidified samples, relative to the CL method measurements. This result implies that the DPD method measures a larger fraction of the Fe released from particles $(>0.4 \mu \mathrm{m})$ after extended storage at $\mathrm{pH} 1.7$ and appears contrary to our argument regarding the solubilization of colloidal Fe in the CL method. We note, however, that the separation and analysis of Fe in the presence of digested and partially digested particulate material in seawater, as in our TDFe samples, might be expected to present even greater complexities than the separation and analysis of Fe in filtered, acidified samples.

Effect of sampling location-The magnitude of the offsets between results of the two analytical methods are likely to reflect both spatial and temporal variations in the seawater samples analyzed. In the $S A Z$ exercise, similar CL and DPD results were obtained for $\mathrm{dFe}$ at station $\mathrm{S} 4$ (Subantarctic Front) and for TDFe at station S6 (Polar Frontal Zone); in the CLIVAR-SR3 exercise, similar CL and DPD results were obtained for dFe at station C1 (Subantarctic Zone). For all other samples analyzed in this study, CL dFe > DPD dFe and DPD TDFe > CL TDFe. If CL determines a larger fraction of organic or colloidal Fe species (as discussed above), then our results would suggest a smaller proportion of organically bound or colloidal Fe at stations S4 and C1. Unfortunately, we have no information on the size-distribution or organic complexation of dissolved Fe for these stations. It is reasonable to expect that Fe concentrations measured by our two FI methods might vary with phytoplankton biomass, community structure, and physiological status, as well as the concentrations of dissolved and particulate organic matter, because these variables are likely to affect iron speciation in the water column. 
Sample storage-Fig. 3 reveals that there was better agreement between the CL and DPD dFe determinations for the $S A Z$ and IRONAGES samples, relative to the freshly collected CLIVAR-SR3 samples. This then suggests that storage of these acidified seawater samples over periods of months to years resulted in the solubilization/dissociation of the colloidal/ organic Fe species to which we attribute our inter-method differences. This is an important result, implying that extended storage of acidified samples may be necessary in order to achieve comparable results for the measurement of "dissolved" iron in seawater using different analytical methods. The outcome of ongoing time-series stability studies using the IRONAGES seawater samples are expected to provide further information in this regard.

Summary-The results of our analytical intercomparison exercises indicate that (1) in general, the CL method measured similar or higher concentrations of dissolved iron ( $\mathrm{dFe})$ than the DPD method; (2) inter-method analytical differences for $\mathrm{dFe}$ were largest for the freshly collected acidified CLIVAR-SR3 samples, compared with the acidified $S A Z$ and IRONAGES samples that had been stored for periods of months to years; (3) inter-method analytical differences for dFe appear to vary in relation to the location and season of sample collection; (4) inter-method analytical differences appear to be related to the size fraction of measured Fe: DPD dissolved Fe $(<0.4 \mu \mathrm{m})$ measurements were in closest agreement with CL soluble Fe $(<0.03 \mu \mathrm{m})$ measurements; (5) in some cases, the inter-method differences for dFe were most pronounced in samples from the upper mixed layer of the water column; and (6) an inter-method comparison for unfiltered acidified TDFe samples showed generally higher concentrations measured by DPD than CL, in contrast to the dFe results.

\section{Discussion}

Our results suggest that the observed differences between these FI methods are largely due to the differential separation and determination of various Fe species in seawater. Based on results of an earlier shipboard intercomparison exercise in the Atlantic Ocean, Bowie et al. (2003) have argued that inter-method inconsistencies reflect differences in the extraction efficiency for various Fe species during preconcentration using a chelating resin (FI methods) or competitive ligand equilibration (cathodic stripping voltammetry). Consistent with this idea, our CLIVAR-SR3 results suggest that inter-method differences in dissolved Fe measurements are related to the presence of colloidal-sized (0.03 to $0.4 \mu \mathrm{m})$ Fe species in surface waters, which are preferentially determined by the CL method. With regard to the biological availability of iron in the ocean, the ability of an analytical technique to separate and measure such species may be crucial, because colloidal-sized Fe species are believed to be less available to phytoplankton than Fe species in the soluble $(<0.03 \mu \mathrm{m})$ size range (Wu et al. 2001). Thus the difference in the concentrations of "dissolved Fe" measured by the
CL and DPD techniques may represent Fe that is not directly available for uptake by phytoplankton.

\section{Comments and recommendations}

With regard to the comparability of dissolved iron measurements in seawater, it is encouraging that we observed reasonably good inter-method agreement for dissolved iron measurements in samples that had been stored over periods of 6 months or more. It may thus be useful to consider the extended storage of acidified samples as a potential protocol for the determination of dissolved iron in seawater. The results of this study suggest several possible directions for the analytical comparison of flow injection methods for iron in seawater. These include a comparison of methods with and without UV oxidation of seawater samples prior to analysis, to investigate the selective determination of organic iron species, as well as a methods comparison using identical sample preconcentration apparatus, to investigate the importance of the separation-preconcentration procedure as a source of analytical discrepancy. A long-term methods comparison using identical samples stored for various periods of time would also be useful in investigating the effect of sample storage on analytical discrepancy. Finally, we note that further intercomparisons for the determination of iron in seawater will be greatly facilitated by the introduction of certified reference materials containing low iron concentrations ( 0.1 to $0.2 \mathrm{nM}$ ).

\section{References}

Achterberg, E. P., T. W. Holland, A. R. Bowie, R. F. C. Mantoura, and P. J. Worsfold. 2001. Determination of iron in seawater. Anal. Chim. Acta 442:1-14.

Bowie, A. R., E. P. Achterberg, R. F. C. Mantoura, and P. J. Worsfold. 1998. Determination of sub-nanomolar levels of iron in seawater using flow injection with chemiluminescence detection. Anal. Chim. Acta 361:189-200.

, M. T. Maldonado, R. D. Frew, P. L. Croot, E. P. Achterberg, R. F. C. Mantoura, P. J. Worsfold, C. S. Law, and P. W. Boyd. 2001. The fate of added iron during a mesoscale fertilisation experiment in the Southern Ocean. Deep-Sea Res. II 48:2703-2743.

—, D. J. Whitworth, E. P. Achterberg, R. F. C. Mantoura, and P. J. Worsfold. 2002a. Biogeochemistry of Fe and other trace elements ( $\mathrm{Al}, \mathrm{Co}, \mathrm{Ni})$ in the upper Atlantic Ocean. Deep-Sea Res. I 49:605-636.

—, E. P. Achterberg, P. N. Sedwick, S. J. Ussher, and P. J. Worsfold. 2002b. Real-time monitoring of picomolar concentrations of iron(II) in marine waters using flow injection-chemiluminescence instrumentation. Environ. Sci. Technol. 36:4600-4607.

, E. P. Achterberg, S. Blain, M. Boye, P. L. Croot, P. Laan, G. Sarthou, H. J. W. de Baar, and P. J. Worsfold. 2003. Shipboard analytical intercomparison of dissolved iron in surface waters along a north-south transect of the Atlantic Ocean. Mar. Chem. 84:19-34. 
Bruland, K. W., and E. L. Rue. 2001. Analytical Methods for the Determination of Concentrations and Speciation of Iron, chapter 6, p. 255-290. In D. R. Turner and K. A. Hunter (eds.), The Biogeochemistry of Iron in Seawater. Wiley.

Coale, K. H., P. J. Worsfold, and H. J. W. de Baar. 1999. Iron age in oceanography. Eos Trans. Am. Geophys. Union 80:377382.

Committee on Reference Materials for Ocean Science. 2002. Chemical reference materials: setting the standards for ocean science, p 37. The National Academies Press.

Falkowski, P. G., R. T. Barber, and V. Smetacek. 1998. Biogeochemical controls and feedbacks on ocean primary production. Science 281:200-206.

Frew, R., A. Bowie, P. Croot, and S. Pickmere. 2001. Macronutrient and trace-metal geochemistry of an in situ ironinduced Southern Ocean bloom. Deep-Sea Res. II 48:24672481.

Hirayama, K., and N. Unohara. 1988. Spectrophotometric catalytic determination of an ultratrace amount of iron(III) in water based on the oxidation of $N, N$-dimethyl- $p$ phenylenediamine by hydrogen peroxide. Anal. Chem. 60:2573-2577.

Klopf, L. L., and T. A. Nieman. 1983. Effect of iron(II), cobalt(II), copper(II), and manganese(II) on the chemiluminescence of luminol in the absence of hydrogen peroxide. Anal. Chem. 55:1080-1083.

Landing, W. M., C. Haraldsson, and N. Paxeus. 1986. Vinyl polymer agglomerate based transition metal cation chelating ion-exchange resin containing the 8-hydroxyquinoline functional group. Anal. Chem. 58:3031-3035.

Martin, J. H., R. M. Gordon, and S. E. Fitzwater. 1990. Iron in Antarctic waters. Nature 345:156-158.

Measures, C. I., J. Yuan, and J. A. Resing. 1995. Determination of iron in seawater by flow injection analysis using in-line preconcentration and spectrophotometric detection. Mar. Chem. 50:3-12.

Moore, J. K., S. C. Doney, D. M. Glover, and I. Y. Fung. 2002. Iron cycling and nutrient-limitation patterns in surface waters of the World Ocean. Deep-Sea Res. II 49:463-507.

Rue, E. L., and K. W. Bruland. 1995. Complexation of iron(III) by natural organic ligands in the central North Pacific as determined by a new competitive ligand equilibration/ adsorption cathodic stripping voltametric method. Mar. Chem. 50:117-138.

Rose, A.L., and T. D. Waite. 2001. Chemiluminescence of luminol in the presence of iron(II) and oxygen: oxidation mechanism and implications for its analytical use. Anal. Chem. 73:5909-5920.

Sedwick, P. N., and G. R. DiTullio. 1997. Regulation of algal blooms in Antarctic shelf waters by the release of iron from melting sea-ice. Geophys. Res. Lett. 24:2515-2518.

—, P. R. Edwards, D. J. Mackey, F. B. Griffiths, and J. S. Parslow. 1997. Iron and manganese in surface waters of the Australian Subantarctic region. Deep-Sea Res. I 44:1239-1253. , G. R. DiTullio, D. A. Hutchins, P. W. Boyd, F. B. Griffiths, A. C. Crossley, T. W. Trull, and B. Quéguiner. 1999. Limitation of algal growth by iron deficiency in the Australian Subantarctic region. Geophys. Res. Lett. 26:2865-2868.

—, G. R. DiTullio, and D. J. Mackey. 2000. Iron and manganese in the Ross Sea, Antarctica: seasonal iron limitation in Antarctic shelf waters. J. Geophys. Res. Oceans 105: 11321-11336.

Seitz, W. R., and D. M. Hercules. 1972. Determination of trace amounts of iron(II) using chemiluminescence analysis. Anal. Chem. 44:2143-2149.

Tschopel, P., L. Kotz, W. Schulz, M. Veber, and G. Tolg. 1980. Causes and elimination of systematic errors in the determination of elements in aqueous solutions in the $\mathrm{ng} / \mathrm{mL}$ and pg/mL range. Fresenius Zeitschrift Fur Analytische Chemie 302:1-14.

Wu, J. F., E. Boyle, W. Sunda, and L. S. Wen. 2001. Soluble and colloidal iron in the oligotrophic North Atlantic and North Pacific. Science 293:847-849.

Submitted 12 July 2003

Revised 18 October 2003

Accepted 13 December 2003 